CONTROL DE MANTENIMIENTO PREVENTIVO EN COMPUTADORES A NIVEL DE SOFTWARE

\title{
CONTROL DE MANTENIMIENTO PREVENTIVO EN COMPUTADORES A NIVEL
} DE SOFTWARE

AUTORES: Zambrano Zambrano Samantha Michelle ${ }^{1}$

Vera Mesías Daniela Jeniffer ${ }^{2}$

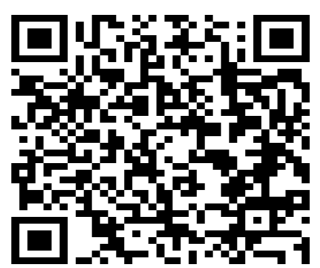

\section{DIRECCIÓN PARA CORRESPONDENCIA: (samizahemosa98@gmail.com)}

Fecha de recepción: 27/01/2020

Fecha de aceptación: 28/02/2020

\section{RESUMEN}

La investigación se basa en el control de mantenimiento preventivo de computadores a nivel de software, teniendo como objetivo primordial la duración extendida de los computadores a nivel de software la cual disminuye los precios de mantenimiento a los beneficiarios.

Para la ejecución del documento se realizó la investigación cumpliendo con el objetivo planteado en el cual se emplearon métodos e instrumentos con el estudio de fuentes y consultas de investigación.

Gracias a los análisis de resultado, se permitió realizar conclusiones que apoyan o rechazan la hipótesis establecida, ubicando esta investigación como un estudio que puede otorgar la pauta a los propios usuarios de realizar mantenimiento preventivo a nivel de software a sus computadores así disminuyen costos a un especialista en dicho trabajo.

PALABRAS CLAVE: software; mantenimiento; computadoras.

\section{CONTROL OF PREVENTIVE MAINTENANCE IN COMPUTERS AT THE SOFTWARE LEVEL}

\section{ABSTRACT}

The research is based in the preventive maintenance of computers control at the software level, having as main objective the extended duration of the computers at the software level which decreases the maintenance prices to the beneficiaries.

For the execution of the document, the research was carried out in compliance with the objective set out in which methods and instruments were used with the study of sources and consultations research.

\footnotetext{
${ }^{1}$ Zambrano Zambrano Samantha Michelle (Bachiller en Aplicaciones Informáticas, Estudiante de Tercer Nivel, Ing. Tecnologías de la Información de la Universidad Estatal del Sur de Manabí, Chone, Costa, Ecuador)

${ }^{2}$ Vera Mesías Daniela Jeniffer (Bachiller en Aplicaciones Informáticas, Estudiante de Tercer Nivel, Ing. Tecnologías de la Información de la Universidad Estatal del Sur de Manabí, Chone, Costa, Ecuador, djvm01_99@hotmail.com)
} 
Zambrano Zambrano Samantha Michelle, Vera Mesías Daniela Jeniffer

Thanks to the analysis results, it was possible to make conclusions that support or reject the hypothesis established, locating this research as a study that can give the guidelines to the users to perform preventive maintenance at the software level to their computers, so reducing costs to a specialist in such work.

KEYWORDS: software; maintenance; computers

\section{INTRODUCCIÓN}

Según lo que plantea Garrido en su libro organización y gestión integral de mantenimiento que “el mantenimiento es el conjunto de técnicas destinados a conservar equipos e instalaciones en servicio durante el mayor tiempo posible (buscando la más alta disponibilidad) y con el máximo rendimiento.” (Garrido, 2010)

Para la elaboración del documento que respalda la investigación y el cumplimiento del objetivo planteado se emplearon una serie de técnicas e instrumentos de recolección de datos, específicamente la observación directa, el análisis de fuentes documentales y consultas que permitieron llevar a cabo con la investigación.

Los conocimientos adquiridos en la elaboración del documento determinaron la importancia del mismo y ayudaron a obtener las conclusiones del análisis del mantenimiento preventivo de software para evitar y reducir problemas en nuestro equipo mejorando su desempeño garantizando su funcionamiento óptimo como un estudio eficaz que puede otorgar la pauta con el usuario.

\section{DESARROLLO}

\section{OBJETIVO}

Maximizar la vida útil de las computadoras a nivel de software y disminuir costos de mantenimiento a los usuarios.

\section{DEFINICIONES}

\section{SOFTWARE}

En su libro ingeniería del software, Pressman señala que "el software de computadora es el producto que construyen los programadores profesionales y al que después le dan mantenimiento durante un largo tiempo. Incluye programas que se ejecutan en una computadora de cualquier tamaño y arquitectura, contenido que se presenta a medida que se ejecutan los programas de cómputo e información descriptiva tanto en una copia dura como en formatos virtuales que engloban virtualmente a cualesquiera medios electrónicos. La ingeniería de software está formada por un proceso, un conjunto de métodos (prácticas) y un arreglo de herramientas que permite a los profesionales elaborar software de cómputo de alta calidad.” (Pressman, 2010:1)

144 UNESUM-Ciencias. Publicación cuatrimestral. Vol. 2, Año 2018, No. 2 (agosto) 
CONTROL DE MANTENIMIENTO PREVENTIVO EN COMPUTADORES A NIVEL DE SOFTWARE

\section{MANTENIMIENTO}

De acuerdo con lo expuesto por Patton "Se define como la disciplina cuya finalidad consiste en mantener al ordenador en estado de operación” (Patton, 1998)

\section{MANTENIMIENTO PREVENTIVO}

De acuerdo con Patton mantenimiento preventivo hace referencia a "la estabilidad de un ordenador en estado de operación optima, por medio de una registro sistemático, detección y prevención de una falla eminente” (Patton, 1998)

\section{CONTENIDO}

\section{MANTENIMIENTO PREVENTIVO A NIVEL DE SOFTWARE}

Según Roger S Pressman “Conforme pasa el tiempo, la organización descubre que emplea más dinero y tiempo en mantener los programas existentes que en someter a ingeniería nuevas aplicaciones. De hecho, no es raro que una organización de software emplee entre 60 y 70 por ciento de todos sus recursos en mantenimiento del software" (Pressman, 2010:1) Cuando un software se libera a los usuarios finales, solo sera cuestion de dias para que se desplieguen un gran cantidad de errores que atacan directamente a los creadores del del software, mientras que al pasar las semanas uno o varios de los que ya utilizan dicha herrramienta digital manifiestan opiniones en cuanto a cambios que se deberian adecuar de modo que se ajuste a sus necesidades y de acuerdo con Roger S Pressman y lo que plante a en la pagina 656 de su libro la "Ingenieria del Software" un enfoque práctico( $7^{\circ}$ Edision) "El reto del mantenimiento del software comienza. Uno se enfrenta con una creciente lista de corrección de errores, peticiones de adaptación y mejoras categóricas que deben planearse, calendarizarse y, a final de cuentas, lograrse. Mucho antes, la fila creció bastante y el trabajo que implica amenaza con abrumar los recursos disponibles.” (Pressman, 2010:1)

Los métodos de desarrollo y mantenimiento del software forjan habitualmente abundante variedad de información a todo esto le podemos agregar que la información no es constante y menos en el ámbito de la tecnología lo que hace referencia a lo dicho por Oliveira "Durante esta etapa la información no sólo proviene de los profesionales involucrados en las actividades de mantenimiento, sino también del propio producto que se mantiene, de las causas que motivaron el mantenimiento, de los clientes y usuarios, así como de los procesos, metodologías y herramientas utilizadas por la organización. Además, la información cambia constantemente debido a la propia naturaleza del mantenimiento, que surge, entre otras razones, de la necesidad de adaptar sistemas software a un entorno que a su vez está siempre evolucionando” (Oliveira, 2003)

Eventualmente los factores que causan las averias en los software son los virus como dice en el libro "Virus Informáticos: teoría y experimentos", del doctor Fred Cohen, quien es reconocido como el primero en definir los virus informáticos, manifesto: "Se denomina virus informático a todo programa capaz de infectar a otros programas, a partir de su modificación para introducirse en ellos” (Cohen, 1984). Por otro lado, los virus informáticos poseen un ciclo de vida, que principia cuando se genera y acaba cuando son eliminados.

Ciclo de vida de un virus

- Gestación. 
- Reproducción.

- Activación.

- Descubrimiento.

- Asimilación

- Eliminación.

A su vez los virus se pueden ser:

- Residentes.

- Virus de acción directa.

- Virus sobre escritura

- Virus de arranque (boot).

- Virus de macro.

- Virus de enlace o directorio.

- Virus encriptados.

- Virus polimórficos.

- Virus multipartitos

- Virus de archivo.

- Virus de compañía.

- Virus FAT

- Caballo de troya ó camaleones.

- Bombas lógicas o de tiempo.

- Retro virus.

- Virus

Según la manifestación de Vieras "el mantenimiento preventivo reside en emplear un encadenamiento de métodos y procedimientos al sistema para disminuir el riesgo de fallo y garantizar su educado funcionamiento durante el mayor tiempo posible, prolongando así su vida utilitaria.” (Vieras, 2011)

Las metodologías perfeccionadas para prevenir los equipos de cómputo personal y acoplado a una red frente a averías ocasionales o intencionales que afectan el funcionamiento tanto del hardware como del software. Son consideradas unas de las herramientas esenciales que los usuarios de materiales de cómputo operan para mantener sus equipos en modo de operacional durante mucho más tiempo. A continuación se mencionan algunos de las aplicaciones informáticas que podemos utilizar para mantener el software de una pc fuera de estos posibles atacantes.

Dentro de las aplicaciones informáticas de antivirus cabe mencionar:

146 UNESUM-Ciencias. Publicación cuatrimestral. Vol. 2, Año 2018, No. 2 (agosto) 
- CCleaner

- ShellMenuView

- Advanced Uninstaller Pro

- Remo MORE

- Tiny Deduplicator

- Privacy Eraser

- $\quad$ Spyware Search \& Destroy

- TuneUp Utilities

- SlimCleaner

- WinUtilities

Cabe mencionar que aparte de las aplicaciones informáticas antes mencionadas también podemos emplear tácticas antivíricas de preparación y prevención, detección de virus, contención y recuperación como las que mencionan Raul Guillermo Alfaro Reyes, Julio César Baños Carmona y Erik Aurelio Zúñiga Ramos en su tesis final:

- "Los usuarios pueden prepararse frente a una infección viral creando regularmente copias de seguridad del software original legítimo y de los archivos de datos, para poder recuperar el sistema informático en caso necesario.” (Raul Guillermo Alfaro Reyes, 2010)

\section{METODOLOGÍA}

\section{Tipos de Investigaciones}

Según la bibliografía constatada existen diferentes tipos de investigaciones tales como:

\section{Investigación Exploratoria}

Según Namakforoosh plantea que la investigación exploratoria "es aquella que capta una perspectiva general del problema. Este tipo de estudio ayuda a dividir un problema muy grande y llega a unos subproblemas más precisos hasta en la forma de expresar las hipótesis.”

(Mohammad Naghi Namakforoosh, 2005)

Se hizo uso de la investigación exploratoria para conocer más sobre el tema que se abordó lo que nos permitió familiarizarnos con la investigación de control de mantenimiento preventivo a nivel de software y verificar si es factible.

\section{Investigación Explicativa}

Según Congreso lo publicado en su libro la investigación explicativa "es aquella que busca el porqué de los hechos mediante el establecimiento de relaciones causa-efecto sus resultados constituyen el nivel más profundos de conocimientos.” (Congreso, 2006)

La presente investigación consiste en el control de mantenimiento preventivo a nivel de software que permite reducir problemas en el sistema garantizando su funcionamiento óptimo y eficaz para con el usuario. 


\section{CONCLUSIONES}

Se concluyó que:

- El mantenimiento preventivo debe realizarse periódicamente cada 3 meses para mejorar su desempeño y así poder detectar a tiempo cualquier falla del computador.

- La limpieza profunda de los archivos innecesarios del computador libera espacio en la memoria y reduce complicaciones en el sistema garantizando su funcionamiento óptimo y eficaz para con el usuario.

- Para evitar problemas en nuestro equipo un mantenimiento preventivo de software utiliza programas especializados que aumentan la velocidad de transferencia de archivos la cual ayudará a disminuir costos de mantenimiento a los usuarios.

\section{RECOMENDACIONES}

Se recomienda:

- Establecer tiempo y fecha exacta para realizar un mantenimiento.

- Hacer un análisis de virus cada 3 meses en el computador.

- Realizar un mantenimiento preventivo a los computadores del cuarto semestre paralelo "B".

\section{REFERENCIAS BIBLIOGRÁFICAS}

Cohen, F. (1984). virus informatico: teoria y experimento.

Congreso, A. L. (2006). Introducción a la investigación bioantropológica en actividad física, deporte y salud. En P. G. Avendaño, Introducción a la investigación bioantropológica en actividad física, deporte y salud (pág. 186 páginas). Caracas, Venezuela: CDCH UCV, 2006.

Garrido, S. G. (2010). En Organización y gestión integral de mantenimiento (pág. 320 páginas). Ediciones Díaz de Santos.

Mohammad Naghi Namakforoosh. (2005). Metodología de la investigación. En M. N. Namakforoosh, Metodología de la investigación (pág. 528 páginas). México: Editorial Limusa, 2000 Namakforoosh.--2a.ed-México:Limusa,2005.

Oliveira, K. M. (2003). Knowledge for Software Maintenance. Fifteenth International Conference on Software Engineering and Knowledge Engineering(SEKE), (págs. 61-68).

Patton, J. (1998). maintainanbility and maintenance management $2^{\circ}$ edision. USA: Instrument society of America.

Pressman, R. S. (2010:1). Ingeneria del Software un Enfoque Pràctico . México : McGRAW-HILL INTERAMERICANA EDITORES, S.A. DE C.V.

Raul Guillermo Alfaro Reyes, J. C. (16 de febrero de 2010). Obtenido de https://tesis.ipn.mx/bitstream/handle/123456789/6039/I2.1156.pdf?sequence=1

Vieras, J. (marzo de 2011). IES.CAMAS. Obtenido de https://sites.google.com/site/pcpicamas/

148 UNESUM-Ciencias. Publicación cuatrimestral. Vol. 2, Año 2018, No. 2 (agosto) 
